\title{
Acute disseminated encephalomyelitis
}

INSERM

\section{Source}

INSERM. (1999). Orphanet: an online rare disease and orphan drug data base. Acute disseminated encephalomyelitis. ORPHA:83597

Acute disseminated encephalomyelitis (ADEM) is a demyelinating disorder of the central nervous system. 